https://helda.helsinki.fi

\title{
Sialendoscopy under local anaesthesia
}

\author{
Jokela, Johanna
}

2017-03

Jokela , J , Haapaniemi , A , Makitie , A \& Saarinen , R 2017 , ' Sialendoscopy under local

anaesthesia ' , Acta Oto-Laryngologica , vol. 137 , no. 3 , pp. 310-314 . https://doi.org/10.1080/00016489.2016.1230

http://hdl.handle.net/10138/311764

https://doi.org/10.1080/00016489.2016.1230681

acceptedVersion

Downloaded from Helda, University of Helsinki institutional repository.

This is an electronic reprint of the original article.

This reprint may differ from the original in pagination and typographic detail.

Please cite the original version. 


\section{Sialendoscopy Under Local Anaesthesia}

Johanna Jokela*, Aaro Haapaniemi, Antti Mäkitie* ${ }^{* \dagger}$, Riitta Saarinen*

Affiliations: *Department of Otorhinolaryngology - Head and Neck Surgery, University of Helsinki and Helsinki University Hospital, Helsinki, Finland, 'Division of Ear, Nose and Throat Diseases, Department of Clinical Sciences, Intervention and Technology, Karolinska Institutet, Karolinska University Hospital, Stockholm, Sweden

Acknowledgements: This study was supported by the Helsinki University Hospital Research Fund

Corresponding author:

MD Johanna Jokela

Department of Otorhinolaryngology - Head and Neck Surgery

Helsinki University Hospital

P.O. Box 263

FI-00029 HUS, Helsinki, Finland

email: jokela.johanna.m@gmail.com

tel: +358407432625 


\section{ABSTRACT}

Conclusions: In most cases, both diagnostic and interventional sialendoscopy are well tolerated under local anaesthesia (LA) or under local anaesthesia with sedation (LAS) with reasonably low patient-reported discomfort. Sialendoscopy can be considered a patient-friendly and relatively painless, gland-preserving, minimally invasive procedure suitable for day surgery.

Objective: To investigate patient experience and compliance in sialendoscopy under LA/LAS.

M ethods: This prospective study was conducted at an academic tertiary-care university hospital. During a period of 22 months 89 patients between ages 16 to 81 years underwent diagnostic or interventional sialendoscopy under LA (20\%) or LAS (80\%). After the operation the patients filled in a questionnaire formulated by the authors concerning their procedure-related experiences. Patients' demographic data, ASA status score, pre- and intraoperative blood pressure and heart rate measurements, affected gland, operation time, intervention type, as well as pre-, peri- and postoperative medication were gathered later from the medical records.

Results: The level of discomfort and pain experienced during the operation was assessed as 'mild' or 'none' by $85 \%$ and $89 \%$ of the patients, respectively. The level of pain experienced after the operation was 'major' in $4 \%$ of patients and 'mild' or 'none' in the majority (87\%) of patients. The patients' estimations showed no significant 
difference between the diagnostic and interventional procedures, although it seems that patients who underwent stone removal by transoral incision experienced the operation as a bit more uncomfortable and painful than other patients. Afterwards $97 \%$ of patients stated that they would agree to a new LA/LAS sialendoscopy in the future if needed. 


\section{INTRODUCTION}

The management of obstructive sialadenitis has rapidly evolved from a conservative treatment or open surgery towards minimally invasive techniques. The effectiveness of diagnostic and interventional sialendoscopy has been shown in many studies [1-3]. However, many procedure-related issues and guidelines still need further examination. No consensus exists regarding appropriate anaesthesia, or the role of prophylactic antibiotics, stents or corticosteroids in sialendoscopy. Many centres use local anaesthesia (LA) as a standard [4], whereas some prefer general anaesthesia (GA) [5].

To date, only a few studies exist on the tolerability of sialendoscopy under LA $[6,7]$.

The advantages of GA are definitive analgesia during surgery, maintaining a safe airway and no need for patient cooperation, whereas LA is less invasive and shortens the total operation and recovery times, which saves hospital resources $[8,9]$. The ideal anaesthetic method should also be pleasant to the patients.

Our institution is an academic tertiary-care university hospital and our sialendoscopy protocol currently recommends LA with or without sedation. We therefore investigated patient experience and compliance of sialendoscopy under LA/LAS in a prospective patient questionnaire study.

\section{PATIENTS AND METHODS}


This study was approved by the institutional Research Ethics Committee. Participation was voluntary and did not affect the patient's treatment.

During M arch 2012 to December 2013, a total of 132 patients underwent 149 sialendoscopies at the Department of Otorhinolaryngology - Head and Neck Surgery, Helsinki University Hospital, Finland. Altogether 89 LA/LAS patients, operated by the two main sialendoscopists conducting this study, participated. Patients operated by other physicians were not included and children under 16 years of age were excluded. Also if the patient did not speak Finnish or was not contacted before the operation he/she was excluded.

Patients were recruited before the operation, on the day of the operation. They were informed that the participation was voluntary and that the decision regarding participation would have no effect on their treatment. Patients were also informed of the confidentiality and anonymity of their answers. The questionnaire forms were given directly to the attending researcher and not the operating physician.

After the operation and prior to discharge, participants filled in a questionnaire formulated by the authors. (Table 1). They rated their sensations (pain, discomfort and nervousness) before, during and after the operation using a scale from 'none' to 'major'. The patients were also asked if they would consent to another sialendoscopy under LA/LAS if necessary in the future. 
Patients' demographic data, general health status defined by the American Society of Anesthesiologists (ASA) status score, intervention type, operation time, pre- and intraoperative blood pressure, heart rate measurements and pre-, peri- and postoperative medication were retrieved from the patient records. The depth of sedation was defined according to the definition by the American Society of Anesthesiologists [10].

We used all-in-one and interventional endoscopes (Storz: 11575 A, 11576 and 11573 A). LA was achieved by $10 \%$ lidocaine-hydrochloride spray and by infiltration of $1 \%$ lidocaine with adrenaline $(1 \mathrm{~mL})$ under the papilla. After progressive papilla dilatation, $1 \%$ lidocaine $(1 \mathrm{~mL})$ was administered into the duct. During the operation, irrigation solution of $1 \%$ lidocaine and $0.9 \%$ sodium chloride at a ratio of $1: 4$ was used. Stones were removed endoscopically using a Dormia basket if possible. Large or immobile stones were removed by making an incision over the stone after an additional infiltration of $1 \%$ lidocaine with adrenaline to the area of incision. Strictures were pushed open gently by the endoscope itself, a salivary duct probe or a micro drill. The procedure was considered interventional if a sialolith was removed, a stricture dilated or either of these was attempted. The sialendoscopy was considered diagnostic if only the duct branches were visualized and mucus rinsed out.

We analyzed statistical parameters with NCSS version 8.0, and used the Spearman Correlation or Cross Tabulation tests to calculate correlations. The correlations were 
also calculated after combining the answers 'major' and 'moderate' to obtain larger groups for analysis. P-values were considered significant if $p<0.05$.

\section{RESULTS}

During the study period, 132 patients underwent 149 sialendoscopies. Fourteen patients (11\%) had their sialendoscopy under GA. LA/LAS was the anesthesia of choice for the remaining 118 patients (89\%; 135/ 149 sialendoscopies). Altogether 89 (75\%) of these LA/LAS patients participated in the study and filled in a questionnaire on their procedure-related experiences. Seven sialendoscopies were bilateral.

The gender, age, ASA score and procedure type of the patients in the study appear in Table 2. The median durations of diagnostic and interventional sialendoscopies were 31 and 49 minutes, respectively. The LA procedure had to be converted to GA once due to a proximal sialolith position and the patient's sensitive gag reflex. In seven (8\%) cases sedation with propofol was needed, and in 64 (72\%) cases $2.5-5 \mathrm{mg}$ fentanyl with or without 2.5-5 mg diazepam for sedation was used to enhance analgesia and patient comfort in addition to LA. In 18 (20\%) cases no medications were used expect LA. According to the ASA depth of sedation scale [10], $20 \%$ of the patients had no sedation, $72 \%$ had minimal sedation and $8 \%$ moderate sedation.

Pre- and intraoperative mean systolic and diastolic blood pressures, pulse rates and mean intraoperative blood saturation levels appear in Table 3. The mean systolic $(p=$ 
0.039 ) and diastolic ( $p<0.001$ ) blood pressures were statistically lower during than before the operation. No statistically significant difference was observed between the mean pulse before and during the operation $(p=0.84)$.

An intervention was performed for 47 (53\%) patients: in 30 (34\%) to remove a sialolith, in $16(18 \%)$ to canalize a stricture and in one to perform both (1\%). Sialolith removal succeeded in 25 (81\%) cases; seven (28\%) were removed using a dormia basket and 18 (72\%) using a transoral incision. A stricture was opened successfully in $16(94 \%)$ cases. Stents were used in two stricture cases. In one case, the stricture could not be dilated and this prevented entry to the hilum. Patients' pre-, peri- and postoperative medications appear in Table 4.

Results of the questionnaire are presented in Table 1. Before the operation, 53\% of patients experienced major or moderate nervousness. Patient nervousness correlated with age and gender. The older the patients, the less nervous they were $(p=0.017)$, and men were less nervous than women $(p=0.0012)$. Nervousness did not correlate with estimations concerning the level of pain or discomfort during the operation or with preoperative pulse or blood pressure. The discomfort level experienced during the operation also correlated with patient age. The older the patients, the less discomfort they felt during the operation ( $p=0.036$ ). No correlations were found between the level of discomfort or pain experienced during the operation and patient gender, the gland involved, intraoperative blood pressure, pulse or procedure type (diagnostic vs. 
interventional). Overall, 85\% (76/89) and 89\% (79/89) of patients respectively assessed the intra-operative discomfort and pain as 'mild' or 'none'.

Patients who underwent sialolith removal through a transoral incision assessed the level of discomfort $(p=0.075, p=0.048)$ and pain $(p=0.063, p=0.053)$ during the operation as higher than others. However, statistical significance was reached only after combining the answers 'major' and 'moderate' to obtain larger groups. A trend for increased pain with longer operation time was also observed $(p=0.056)$. M en estimated the level of pain after the operation as lower than women $(p=0.034)$ and patients whose sialoliths were removed using a transoral incision as higher than others $(p=$ 0.016). No correlations were found between the level of post-operative pain and age, the gland involved, procedure type (diagnostic vs. interventional) or the operation time. In all, $87 \%(77 / 89)$ of patients experienced the pain as 'mild' or 'none' after the operation.

The majority of patients $(86 / 89,97 \%)$ stated they would agree to an LA/LAS procedure again in the future if necessary. One (1.1\%) patient stated that he/ she would refuse an LA/LAS procedure and two (2.2\%) did not respond to the question.

Of the 29 LA/LAS sialendoscopy patients not included into this study $45 \%$ had a diagnostic sialendoscopy and 55\% had an interventional sialendoscopy. Of the 14 GA sialendoscopies a sialolith removal was performed for 10/14 (71\%) patients. Two had a parotid stone extracted by combined external-endoscopic approach and five had several sialoliths (from four to six) or a sialolith situated deep in the gland and the 
procedures were estimated to be complex. Six patients had major anxiety regarding the operation and they requested a GA procedure and one had mental retardation with cooperation problems, necessitating GA. The mean operation time was 39 minutes in diagnostic and 58 minutes in interventional sialendoscopy. Three GA patients had undergone an LA/LAS sialendoscopy previously.

\section{DISCUSSION}

Sialendoscopy has become the method of choice in diagnosing and treating obstructive sialadenitis. Our study is one of the first to assess patient experiences of sialendoscopy under LA/ LAS. Due to the lack of a validated questionnaire - which may be regarded as the main weakness of this study - we developed a questionnaire de novo to assess these experiences.

There are no agreements or official recommendations concerning the anaesthetic methods for sialendoscopy. It appears that many centres in Europe use LA or LAS $[4,11,12]$, whereas GA is generally favoured in the USA $[5,13,14]$. It seems logical that minor procedures in the head and neck region should be safer under LA, but we did not find comparative studies to support this. At least some side effects of GA, such as postoperative nausea and vomiting, are avoided when using LA [15]. In studies regarding sinonasal surgery under LAS versus GA, LAS was associated with shorter 
operation time, faster patient recovery, and shorter hospital stay, lowering the burden on hospital resources [8,9]. Daskaya et al. concluded that septoplasty under LAS is more cost-effective than under GA [8]. In a study of 50 patients who had external dacryocystorhinostomy under LA (the use of sedation was not discussed) on one side and under GA on the other, Knezevic et al. found that patients were more satisfied with LA than GA and $94 \%$ of them would prefer LA during the next procedure [16]. In a study of 84 patients, Luers et al. showed that the majority of patients (80\%) tolerated sialendoscopy well under LA [6]. In their study, sedation with $7.5 \mathrm{mg}$ midazolam or $1 \mathrm{~g}$ of flunitrazepam was administered $30 \mathrm{~min}$ prior to the procedure. They recommend LA for patients in good general health when the procedure is not expected to be complex or long [6]. In our study, we observed a trend towards increased pain associated with longer procedures, but this did not reach statistical significance ( $p=0.056)$. Nearly $90 \%$ of patients assessed their levels of discomfort and pain during the operation as 'mild' or 'none'. Patients whose sialoliths were removed using a transoral incision assessed the level of pain and discomfort during the operation and pain after the operation as higher than others, but otherwise no significant difference between the diagnostic and interventional procedures was observed. Although the majority of patients were nervous before the operation, $97 \%$ stated afterwards that they would agree to a new LA/LAS sialendoscopy in the future if needed. In only $3 \%$ of the cases, conversion from LAS to GA during the procedure or the booking of a later GA procedure was necessary. Kopec et al. evaluated the subjective 
overall satisfaction with sialendoscopy in patients with sialolithiasis. The procedure was performed under LA, but no information was given regarding the use of sedation. In this series of 100 patients, $81 \%$ assessed the procedure as very good or good. The authors concluded that sialendoscopy can be performed under LA without exposing patients to increased discomfort, pain or unpleasant experiences [17].

In our opinion GA should be used for non-cooperative or young patients and in cases where sialolith extraction fails under LA/LAS or stone removal is expected to be complex. In addition, favouring LA/ LAS becomes more feasible as the surgeon's experience grows. We are currently gaining experience in extracting sialoliths from the parotid gland by a combined endoscopic-external approach under LA/LAS, but GA is still favoured for this type of procedure. This is also the trend in the literature [18]. Children under 16 years of age were excluded from our study, but Konstantinidis et al. proposed that diagnostic sialendoscopy under LA may be an alternative for children older than eight years of age [7].

During the study period we performed $9 \%$ of adult sialendoscopies under GA for patients whose procedures were anticipated to be complex and for patients with cooperation problems. A controlled prospective randomized trial comparing LA/LAS with GA would reveal the patients' favoured anaesthesia method and whether the total operative and recovery times, postoperative recovery and complications differ among these groups. 
Diagnostic and interventional sialendoscopies are well tolerated and feasible under LA or LAS with reasonably low patient-reported discomfort and pain. LA/ LAS is a safe anaesthetic method for the majority of sialendoscopy patients. However, preoperative patient information, good and timely anxiolysis and analgesia, and good communication with the patient during the procedure are keys to the success of an LA/LAS procedure. M ost of patients would agree to a new LA/LAS procedure again in the future. Complex procedures with difficult anatomic preconditions, cooperation problems or very long expected operation times, favour the use of GA.

\section{ACKNOWLEDGEM ETS}

This study was supported by the Helsinki University Hospital Research Fund. No conflicts of interest are declared. 


\section{REFERENCES}

[1] M archal F, Dulguerov P. Sialolithiasis management: the state of the art. Arch Otolaryngol Head Neck Surg 2003;129:951-6.

[2] Nahlieli O, Nakar LH, Nazarian Y, Turner MD. Sialoendoscopy: A new approach to salivary gland obstructive pathology. J Am Dent Assoc 2006;137:1394-400.

[3] Pace C, Hwang KG, Papadaki M, Troulis M. Interventional Sialendoscopy for Treatment of Obstructive Sialadenitis. American Association of Oral and Maxillofacial Surgeons 2014:2157-66.

[4] Schwartz N, Hazkani I, Goshen S. Combined approach sialendoscopy for management of submandibular gland sialolithiasis. Am J Otolaryngol 2015;36:632-5. [5] Vashishta R, Gillespie M B. Salivary endoscopy for idiopathic chronic sialadenitis. Laryngoscope 2013;123:3016-20.

[6] Luers JC, Stenner M, Schinke M, Helmstaedter V, Beutner D. Tolerability of sialendoscopy under local anesthesia. Ann Otol Rhinol Laryngol 2012;121:269-74.

[7] Konstantinidis I, Chatziavramidis A, Tsakiropoulou E, Malliari H, Constantinidis ]. Pediatric sialendoscopy under local anesthesia: limitations and potentials. Int J Pediatr Otorhinolaryngol 2011;75:245-9.

[8] Daskaya H, Yazici H, Dogan S, Can IH. Septoplasty: under general or sedation anesthesia. Which is more efficacious? Eur Arch Otorhinolaryngol 2014;271:2433-6. 
[9] Fedok FG, Ferraro RE, Kingsley CP, Fornadley JA. Operative times, postanesthesia recovery times, and complications during sinonasal surgery using general anesthesia and local anesthesia with sedation. Otolaryngol Head Neck Surg 2000;122:560-6. [10] American Society of Anesthesiologists Task Force on Sedation and Analgesia by Non-Anesthesiologists. Practice guidelines for sedation and analgesia by nonanesthesiologists. Anesthesiology 2002;96:1004-17.

[11] Koch M , Zenk J, Bozzato A, Bumm K, Iro H. Sialoscopy in cases of unclear swelling of the major salivary glands. Otolaryngol Head Neck Surg 2005;133:863-8.

[12] Kopec T, Wierzbicka M, Szyfter W, Leszczynska M . Algorithm changes in treatment of submandibular gland sialolithiasis. Eur Arch Otorhinolaryngol 2013;270:2089-93. [13] Maresh A, Kutler DI, Kacker A. Sialoendoscopy in the diagnosis and management of obstructive sialadenitis. Laryngoscope 2011;121:495-500.

[14] Pace CG, Hwang KG, Papadaki ME, Troulis MJ. Sialadenitis Without Sialolithiasis Treated by Sialendoscopy. J Oral M axillofac Surg 2015;73:1748-52

[15] Stadler M , Bardiau F, Seidel L, Albert A, Boogaerts JG. Difference in risk factors for postoperative nausea and vomiting. Anesthesiology 2003;98:46-52.

[16] Knezevic M M, Vlajkovic GP, Stojkovic MZ, Rasic DM , Stankovic BR, Bozic M M . Comparison of postoperative pain and satisfaction after dacryocystorhinostomy in patients operated on under local and general anesthesia. M ed Sci M onit 2012;18:CR265-70. 
[17] Kopec T, Wierzbicka M, Piskadlo K, Bednarek M, Szyfter W. Sialendoscopy - a diagnostic and therapeutic approach subjectively rated by patients. Wideochir Inne Tech Maloinwazyjne 2014;9:505-10.

[18] Overton A, Combes J, M cGurk M. Outcome after endoscopically assisted surgical retrieval of symptomatic parotid stones. Int J Oral M axillofac Surg 2012;41:248-51.

Corresponding author:

MD Johanna Jokela

Department of Otorhinolaryngology - Head and Neck Surgery

Helsinki University Hospital

P.O. Box 263

FI-00029 HUS, Helsinki, Finland

email: jokela.johanna.m@gmail.com

tel: +358407432625 
Table 1. Questions presented to patients after sialendoscopy and patient responses on a scale from 'major' to 'none'.

\begin{tabular}{|l|l|l|l|l|}
\hline & \multicolumn{3}{l|}{ Answer, no. (\%) } \\
\hline Question & Major & Moderate & Mild & None \\
\hline $\begin{array}{l}\text { The level of nervousness/anxiety } \\
\text { experienced before the operation? }\end{array}$ & $23(26)$ & $24(27)$ & $26(29)$ & $16(18)$ \\
\hline $\begin{array}{l}\text { The level of discomfort experienced during } \\
\text { the operation? }\end{array}$ & $1(1.1)$ & $12(13)$ & $37(42)$ & $39(44)$ \\
\hline $\begin{array}{l}\text { The level of pain experienced during the } \\
\text { operation? }\end{array}$ & $1(1.1)$ & $9(10)$ & $47(53)$ & $32(36)$ \\
\hline $\begin{array}{l}\text { The level of pain experienced after the } \\
\text { operation? }\end{array}$ & $4(4.5)$ & $8(9.0)$ & $39(44)$ & $38(43)$ \\
\hline
\end{tabular}

Table 2. Patient demographics, ASA score and procedure type.

\begin{tabular}{|l|l|l|l|}
\hline & $\begin{array}{l}\text { Submandibular } \\
\text { gland }\end{array}$ & Parotid gland & All \\
\hline Patients & 46 & 43 & 89 \\
\hline Mean age, years (range) & $45(16-68)$ & $55(27-81)$ & $50(16-81)$ \\
\hline Gender, No. (\%) & & & \\
\hline Women & $20(43)$ & $30(70)$ & $50(56)$ \\
\hline Men & $26(57)$ & $13(30)$ & $39(44)$ \\
\hline ASA score, No. (\%) & & & \\
\hline 1 & $31(67)$ & $16(37)$ & $47(53)$ \\
\hline
\end{tabular}




\begin{tabular}{|l|l|l|l|}
\hline 2 & $13(28)$ & $18(42)$ & $31(35)$ \\
\hline 3 & $2(4)$ & $9(21)$ & $11(12)$ \\
\hline 4 & $0(0)$ & $0(0)$ & $0(0)$ \\
\hline Procedure type, No. (\%) & & & \\
\hline Diagnostic sialendoscopy & $16(35)$ & $26(60)$ & $42(47)$ \\
\hline Interventional sialendoscopy & $30(65)$ & $17(40)$ & $47(53)$ \\
\hline
\end{tabular}

Table 3. M ean pre- and intraoperative cardiovascular parameters

\begin{tabular}{|l|l|}
\hline Preoperative & \\
\hline M SBP*, mmHg (range) & $138(98-193)$ \\
\hline M DBP**, mmHg (range) & $84(61-108)$ \\
\hline M ean pulse, bpm (range) & $71(50-106)$ \\
\hline Intraoperative & \\
\hline M SBP*, mmHg (range) & $135(99-180)$ \\
\hline M DBP**, mmHg (range) & $78(55-111)$ \\
\hline M ean pulse, bpm (range) & $72(51-111)$ \\
\hline M ean blood saturation, \% (range) & $97(93-100)$ \\
\hline
\end{tabular}

*mean systolic blood pressure

**mean diastolic blood pressure

$\mathrm{mmHg}$ - millimetres of mercury, bpm - beats per minute

Table 4. Pre-, peri- and postoperative medication.

\begin{tabular}{|l|l|l|l|}
\hline & Women & Men & All patients \\
\hline
\end{tabular}




\begin{tabular}{|l|l|l|l|}
\hline & 50 & 39 & 89 \\
\hline Preoperative medication, $\mathbf{n}(\%)$ & & & \\
\hline Paracetamol & $37(74)$ & $27(69)$ & $64(72)$ \\
\hline Ibuprofen & $10(20)$ & $7(18)$ & $17(19)$ \\
\hline Diazepam & $23(46)$ & $8(21)$ & $31(35)$ \\
\hline None & $2(4)$ & $5(13)$ & $7(8)$ \\
\hline Perioperative medication, $\mathbf{n}(\%)$ & & & \\
\hline Fentanyl & $37(74)$ & $27(69)$ & $64(72)$ \\
\hline Diazepam & $14(28)$ & $9(23)$ & $23(26)$ \\
\hline Propofol & $4(8)$ & $3(8)$ & $7(8)$ \\
\hline None & $10(20)$ & $8(21)$ & $18(20)$ \\
\hline Postoperative medication, $\mathbf{n}(\%)$ & & & $7(8)$ \\
\hline Paracetamol & $4(8)$ & $3(8)$ & $17(19)$ \\
\hline Ibuprofen/ketoprofen & $12(24)$ & $5(13)$ & $60(67)$ \\
\hline Paracetamol-codeine/tramadol & $6(12)$ & $2(5)$ & $(74)$ \\
\hline None & $31(62)$ & & \\
\hline
\end{tabular}

